\title{
Study on Efficient Time Domain Fatigue Analysis of Mooring Chain by Representative Mean Position
}

\author{
Jeongmoon Park*, Yooil Kim ${ }^{*}$ and Jeong-Hwan Kim ${ }^{*}$ \\ *Department of Naval Architecture and Ocean Engineering, Inha University, Incheon, Korea

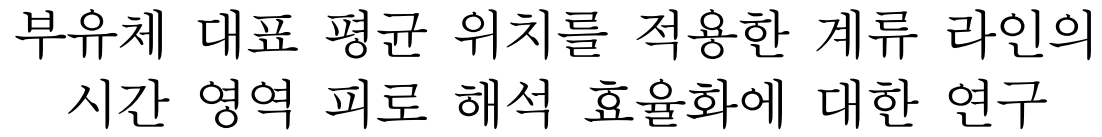 \\ 박정문 ${ }^{*}$ 김유일@* 김정환 \\ *인하대학교 조선해양공학과
}

KEY WORDS: Mooring line 계류 라인, Fatigue damage 피로 손상도, Representative mean position 대표 평균 위치, De-coupled analysis 비연성 해석, Offset 오프셋

\begin{abstract}
This paper addresses the concept of the representative mean position, which was devised to improve the numerical efficiency of a time domain fatigue analysis of a mooring chain. To investigate the influence of an artificial offset of the floater on the fatigue of the mooring chain, a parametric study was performed on the moored FPSO under various combinations of offsets and environmental conditions. Tension time histories were calculated using the de-coupled analysis method, and fatigue damages were calculated to determine the influence of the offset. The parametric study was extended to a more realistic case to determine the actual effect of the representative mean position, where a comparison was made between the two different analysis results, one using the representative mean position and the other one using the actual mean position. It was confirmed that the application of the representative mean position guaranteed the conservatism of the fatigue damage with the enhanced numerical efficiency in the time domain fatigue analysis.
\end{abstract}

\section{1. 서 론}

해양구조물은 수십 년 동안 거친 해상환경으로부터 안전하게 위치 유지를 하면서 작업할 수 있도록 제작되는 것이 필수적이 며 이를 위해 구조적으로 건전한 계류시스템의 확보는 매우 중 요한 설계 인자 중의 하나이다. 계류시스템은 부유식 해양구조 물의 위치 유지를 위한 것으로서 해양구조물의 작업 기간 동안 발생 가능한 모든 해상 환경으로부터 안전하도록 설계되어야 하는데 특히, 장기간 반복적으로 작용하는 파랑하중에 적절히 저항할 수 있는 피로 강도를 확보하는 것이 무엇보다 중요하다. 피로해석은 계류시스템과 같이 장시간 반복 하중에 노출되는 구조물을 설계할 때 수행되어야 하는 중요한 설계 절차 중 하 나로써, 해석 방법 또한 다양하여 구조물의 특성과 하중에 대한 분석을 바탕으로 알맞은 방법을 선택해야 한다. 일반적으로 계 류된 해양구조물의 피로 해석은 2차 파 표류력과 계류라인의 대변형으로 인해 비선형성을 나타내므로 정확한 해석 값을 도
출하기 위해서는 시간영역에서 수행되어야 한다(Kang et al., 2016). 하지만 장시간의 작업기간 동안 발생하는 환경조건들을 모두 고려하여 시간영역 시뮬레이션을 실행하기에는 많은 계산 량과 시간이 소요된다. 따라서 고려해야 할 환경조건을 간소화 할 수 있는 적절한 방법이 필요하다(Kim, 2017; Harald et al., 2005; Harald et al., 1998). Low and Langley(2008)는 부유체-계류 라인 연성 시스템의 동적 거동해석을 위해 복합 시간/주파수 영 역 해석법을 제안하였다. 그들은 저주파수 응답을 위해 시간 영 역해석법을 파 주파수 응답을 위해 주파수 영역해석법을 혼합 적으로 적용하는 방법을 제안하였으며 그 효율성을 입증하였다. $\operatorname{Low}(2011)$ 는 후에 그들이 제안한 방법을 부유체에 연결된 계류 라인과 라이저의 피로해석에 적용하였으며 시간영역에서 수행 된 직접해석의 결과와의 비교를 통해 그 유효성을 입증하였다. 본 연구에서는 피로해석에서 고려해야 할 환경조건을 줄일 수 있도록 부유체의 대표 평균 위치를 이용한 방법을 검토하였 다. 계류라인의 피로해석에 고려되어야 할 단기해상상태는 파

Received 17 July 2018, revised 29 September 2018, accepted 18 October 2018

Corresponding author Yooil Kim: +82-32-860-7347, yooilkim@inha.ac.kr ORCID: http://orcid.org/0000-0002-7540-761X

(C) 2018, The Korean Society of Ocean Engineers

This is an open access article distributed under the terms of the creative commons attribution non-commercial license (http://creativecommons.org/licenses/by-nc/3.0) which permits unrestricted non-commercial use, distribution, and reproduction in any medium, provided the original work is properly cited. 
랑하중, 1 차 $/ 2$ 차 너울, 조류 및 바람 등의 조합에 따라 매우 많 은 경우의 수를 가지게 되며 이는 시간영역 해석의 큰 걸림돌 로 작용한다. 이들 중 조류하중 및 풍하중은 파랑하중 및 너울 과 달리 주로 부유체의 평균 위치에만 관여하는 비변동하중 성 분으로 가정함이 가능하므로 부유체 평균 위치에 대한 합리적 이고 적절한 고려가 가능하다면 단기해상상태의 경우의 수에서 제외하여 시간영역 해석의 효율화를 도모할 수 있다. 대표 평균 위치(Representative mean position)는 이러한 개념에 기반한 것으 로 이의 적용을 통해 계류라인의 보수적인 피로 손상도를 얻을 수 있고, 많은 시간이 소요되는 계류라인의 시간영역 거동해석 을 위해 고려해야 할 환경조건의 수를 줄일 수 있는 장점을 가 지고 있다.

대표 평균 위치는 조류하중과 풍하중 하에서 수행되는 정적 해석으로부터 얻어지는 부유체의 평균 오프셋에 바탕을 둔 개 념으로, 그 적용 가능성을 위해서 계산된 계류라인의 피로수명 이 충분히 보수적인 결과를 주는 것을 입증할 필요가 있다. 본 연구에서는 대표 평균 위치를 이용한 방법의 보수성을 입증하 기 위해 서로 다른 인위적인 초기 오프셋을 갖는 부유체의 계 류라인에 대한 피로해석을 수행하였다. 또한, 오프셋 효과에 대 한 해석의 결과를 입증하기 위해 실 프로젝트에 기반한 사례해 석을 수행하였으며, 이를 통해 대표 평균 위치의 적용성을 평가 하였다.

\section{2. 해석 절차}

\section{1 피로해석 절차}

계류라인의 피로 수명을 도출하기 위해 Fig. 1과 같은 해석 절차에 따라 피로 해석을 수행하였다. 계류라인의 장력을 얻기 위한 해석은 부유체의 운동과 계류라인 동역학 거동의 연성효 과를 고려하지 않는 비연성 해석법을 이용하였다. 비연성 해석 법에서는 계류된 해양구조물의 운동해석 시에 계류라인이 준정 적 거동을 하는 것으로 가정하고 현수선 방정식을 적용하여 계 류라인의 거동 해석을 진행하게 되는데, 본 연구에서는 상용프 로그램인 ARIANE7을 사용하여 해석을 수행하였다(Bureau Veritas, 2012). 식 (1) 및 식 (2)는 파랑하중에 의한 부유체의 운 동방정식이며, 각각 병진(상하동요, 전후동요, 좌우동요) 및 회 전운동(횡요, 종요, 선수요)을 나타낸다. $m$ 은 부유체의 질량이 며, $I$ 는 2 차 관성모멘트이다. $F_{h}$ 는 부유체의 유체역학적 힘이 며, $F_{w}$ 는 파랑 하중에 의한 외력을 나타낸다.

$$
\begin{aligned}
& m \ddot{x}=F_{h}+F_{w} \\
& I \ddot{\theta}=M_{h}+M_{w}
\end{aligned}
$$

계류라인의 장력을 얻기 위해 전술한 해석을 통해 얻어진 부 유체의 운동응답을 계류라인의 최상단에 강제변위의 형태로 부 가하여 과도 동적해석을 수행하였다. 계류라인의 동적 거동은 ORCAFLEX를 통해 수행되었는데, 해석 대상인 계류라인을 트 러스 요소로 공간 이산화하고 음해(Implicit) 유한차분법을 통해 시간영역 해석을 수행하였다. 또한, 일반적으로 계류라인의 변 형 양상은 대변형 및 응력 강화(Stress stiffening) 등을 유발할 수

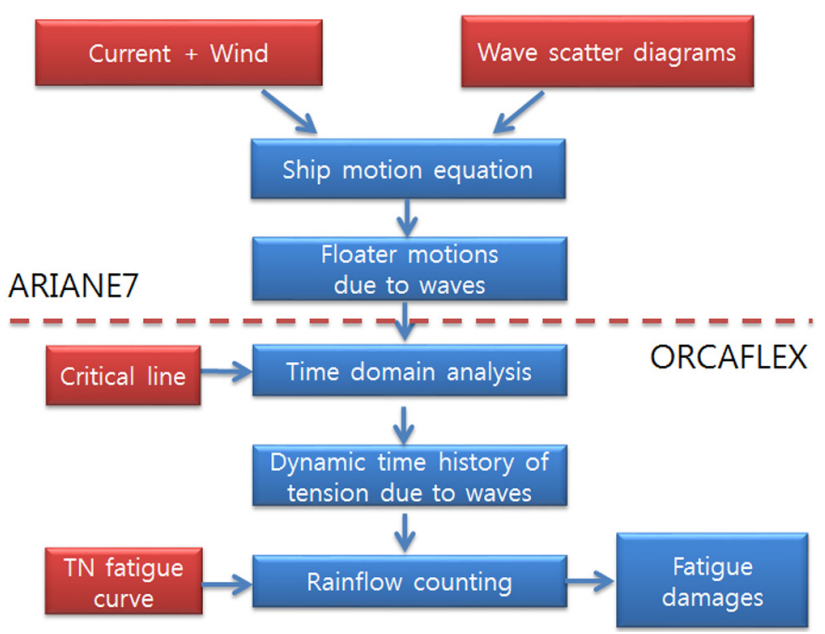

Fig. 1 Fatigue analysis procedure

있으므로 기하학적 비선형 효과를 고려하여 시스템의 강성행렬 이 변형에 따라 지속적으로 변화하도록 하였다. 계류라인 동적 거동해석에서는 해석의 효율성을 위해 피로 손상도가 가장 클 것으로 예상되는 대표 계류라인 하나만을 모델링하여 해석을 수행하였다.

\section{2 부유체 평균 위치}

본 연구에서 검토하고자 하는 대표 평균 위치 개념의 도입이 계류라인의 피로 수명에 미치는 영향을 알아보기 위해 일반적 인 운동해석 절차인 실제 평균 위치(Actual mean position)를 이 용한 해석 결과와 대표 평균 위치를 이용한 해석 결과를 비교 하였다.

Fig. 2는 실제 평균 위치를 이용한 방법에 대한 유체동역학 해석 절차를 나타낸다. 실제 평균 위치를 이용한 운동해석은 파 랑 및 1차/2차 너울과 함께 조류하중과 풍하중을 함께 고려한 단기해상상태를 적용하는 방법으로서, 해석에 고려된 모든 단 기해상상태가 서로 다른 평균 위치를 가지게 된다. 시간영역 해 석이 시작되면 조류하중과 풍하중 및 2 차 파랑 표류력에 의해 부유체가 초기 위치에서 평균 위치로 이동하게 되며, 이어서 변 동하는 파랑하중에 의해 부유체가 6자유도 운동을 하게 된다.

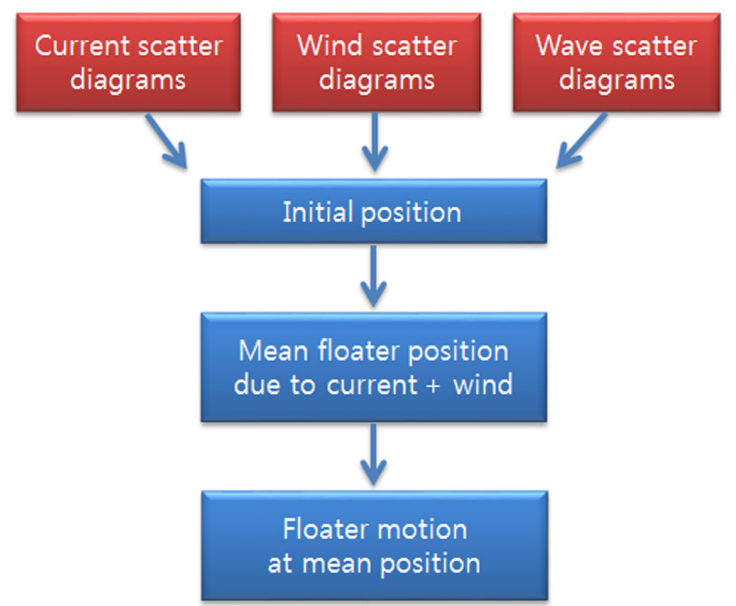

Fig. 2 Procedure of the actual mean position method 
실제 평균 위치를 이용한 방법은 환경하중에 노출되는 해양 구조물의 실제 상황을 그대로 모사하는 방식이 때문에 보다 실 제와 가까운 해석 결과를 얻을 수 있는 장점이 있으나 $(\mathrm{DNV}$, 2010) 피로 손상도를 유발하는 변동하중이 아닌 조류하중과 풍 하중을 단기해상상태의 집계에 고려함으로 인해 지나치게 많은 하중 조건을 만들어내는 단점이 있다.

실제 평균 위치가 가지는 단점을 극복하기 위해 대표 평균 위 치의 개념을 도입하여 해석에 필요한 단기해상상태의 개수를 줄여 시간영역 해석의 효율화를 도모하고자 한다. 대표 평균 위 치는 조류하중과 풍하중에 의해 발생하는 다양한 부유체의 평 균 위치들 중, 계류라인 장력이 상위 $1 / 3$ 에 해당하는 위치의 평 균으로 정의한다. 대표 평균 위치는 환경조건의 발현확률을 고 려하여 식 (3)을 통해 계산할 수 있다.

$$
\vec{X}=\frac{\sum_{\text {upper }}{\overrightarrow{X_{i}}}_{i / 3} p_{i}}{\sum_{\text {tension }} p_{i}}
$$

여기서 $\vec{X}_{i}$ 는 조류하중 및 풍하중에 대한 단기해상상태의 평균 위치를, $p_{i}$ 는 해당 단기해상상태의 발현 확률을 의미한다.

Fig. 3은 대표 평균 위치를 이용한 유체동역학 해석 절차를 나타낸다. 대표 평균 위치는 조류하중, 풍하중에 대해 순차적으 로 계산되는 것으로, 먼저 조류하중에 의한 대표 평균 위치가 결정되면 해당 위치를 초기 위치로 하여 풍하중에 대한 대표 평균 위치를 계산하게 된다. 파랑 하중 및 1 차 $/ 2$ 차 너울에 의한 동적 운동응답은 조류하중과 풍하중에 의해 결정된 대표 평균 위치를 초기 위치로 간주하고 수행된다.

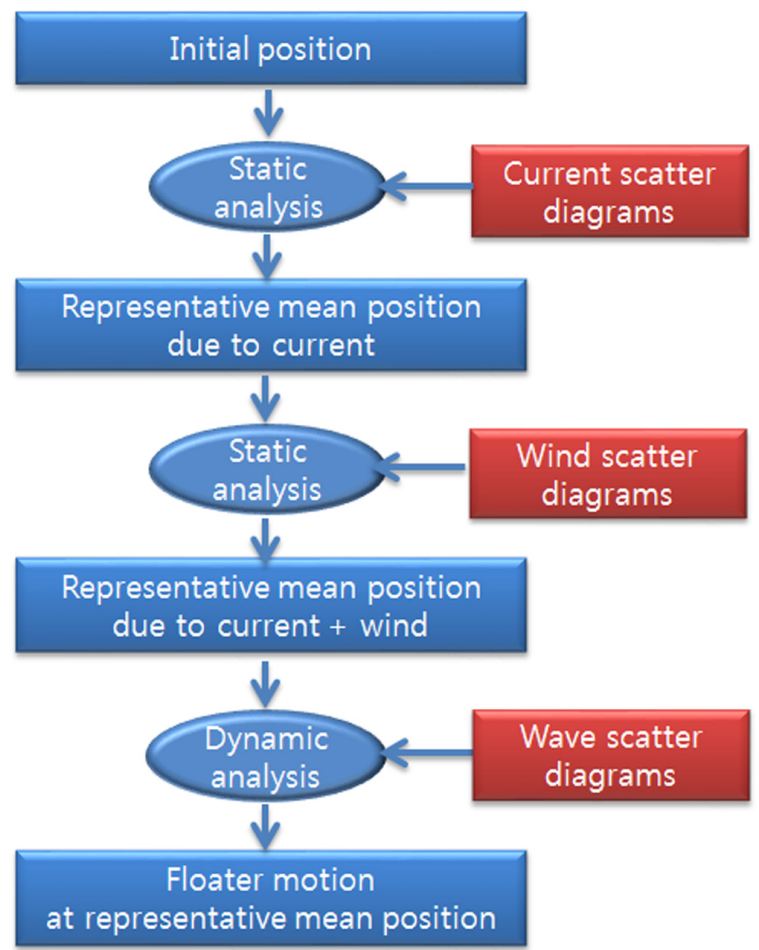

Fig. 3 Procedure of the representative mean position method

\section{3. 해석 모델}

본 연구에 사용된 해양구조물은 박스 형상의 FPSO(Floating production storage and offloading)로써, 길이 $300 \mathrm{~m}$, 폭 $60 \mathrm{~m}$, 흘수 $25 \mathrm{~m}$ 를 가진다. 부유체에 대한 보다 상세한 정보는 Table 1 에 기 술하였다.

부유체를 구속하는 계류시스템은 Fig. 4에 보인 바와 같이 각 각 3 개의 계류라인으로 구성된 4개의 번들로 이루어져 있으며 계류라인 사이의 내부 각도는 $4^{\circ}$ 이며 번들 최외각 계류라인 간 의 외부 각도는 $60^{\circ}$ 이다. $\mathrm{FPSO}$ 의 선수방향은 무게중심 좌표를 기준으로 시계방향으로 $202.5^{\circ}$ 에 위치해 있다.

계류라인은 현수선 방식으로 상부 체인, 와이어 로프 그리고 하부 체인으로 이루어져있다. 상부 체인은 $152 \mathrm{~mm}$ R4S Studless 이며 길이는 $40 \mathrm{~m}$ 이며, 와이어 로프는 $108 \mathrm{~mm}$ Spiral strand로 길 이는 약 $1,967 \sim 2,000 \mathrm{~m}$ 이다. 해저면 체인은 $127 \mathrm{~mm} \mathrm{R3} \mathrm{Studless이}$ 며, 길이는 $855 \mathrm{~m}$ 이다. 계류라인에 대한 자세한 정보는 Table 2 에 기술하였다.

Table 1 Main dimensions of the FPSO

\begin{tabular}{cc}
\hline \hline Item & Value \\
\cline { 2 - 2 } & Full loading condition \\
\hline LBP [m] & 300 \\
Breadth [m] & 60 \\
Depth [m] & 34 \\
Hull weight [ton] & 85,000 \\
Draft [m] & 25 \\
Displacement [ton] & 442,312 \\
GM [m] & 3.862 \\
\hline
\end{tabular}

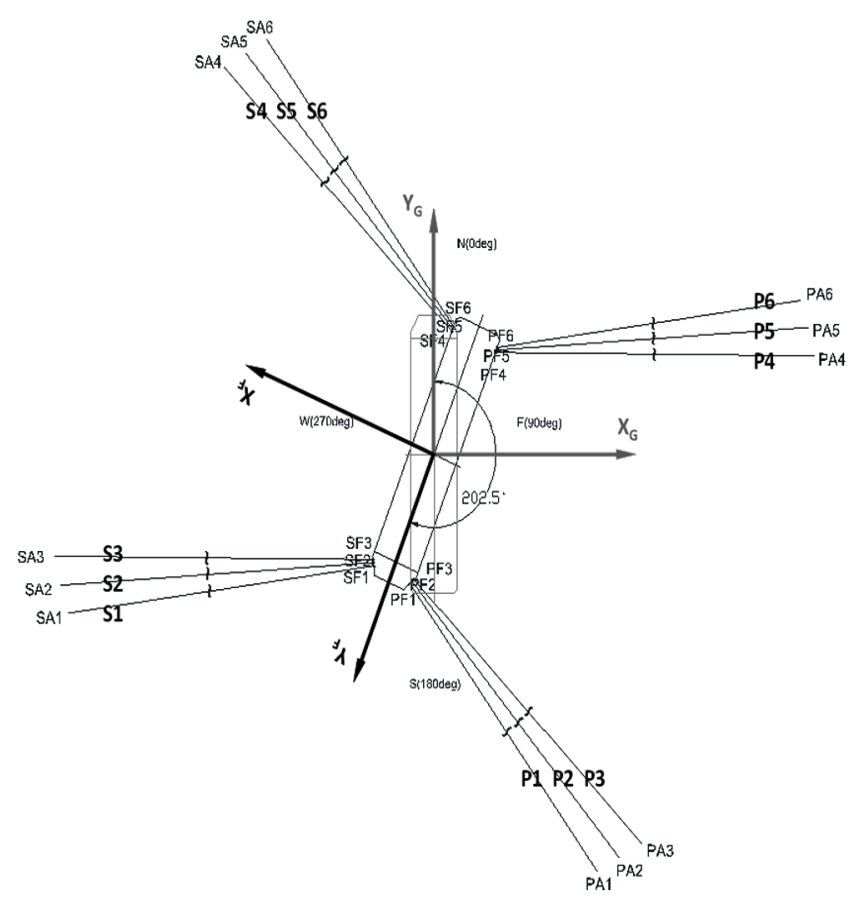

Fig. 4 Mooring system layout 
Table 2 Dimension of mooring line composition

\begin{tabular}{ccc}
\hline \hline & Type & $152 \mathrm{~mm}$ R4S Studless \\
\cline { 2 - 3 } Top chain & Length $[\mathrm{m}]$ & 40 \\
& MBL intact $[\mathrm{kN}]$ & 22363 \\
& MBL full corroded $[\mathrm{kN}]$ & 16592 \\
& Weight in air $[\mathrm{kg} / \mathrm{m}]$ & 462 \\
\cline { 2 - 3 } Wire rope & Type & $108 \mathrm{~mm}$ Spiral strand \\
& Length $[\mathrm{m}]$ & $1967 \sim 2000$ \\
& MBL $[\mathrm{kN}]$ & 12814 \\
Wround & Type & 61.3 \\
\cline { 2 - 3 } chain & Length $[\mathrm{m}]$ & 855 \\
& MBL* intact $[\mathrm{kN}]$ & 12171 \\
& Weight in air $[\mathrm{kg} / \mathrm{m}]$ & 323 \\
\hline
\end{tabular}

* : Maximum Breaking Load

\section{4. 오프셋 효과}

3절에서 소개한 $\mathrm{FPSO}$ 의 제원을 바탕으로 부유체의 오프셋이 계류 라인의 피로 손상에 미치는 영향을 알아보기 위한 사례 해석을 수행하였다. 이를 위해 유의파고 $0.5 \mathrm{~m}$, 모달주기 $13.5 \mathrm{sec}$ 를 가지는 JONSWAP(Joint North Sea wave project) 스펙트럼을 통해 불규칙 파를 생성하고 다양한 입사각에 대한 해석을 수행 하였다. 불규칙 파의 입사각은 $0 \sim 360^{\circ}$ 를 $45^{\circ}$ 간격으로 균등 분할 하였다.

오프셋이 피로 손상에 미치는 영향을 파악하기 위해 비연성 해석기법을 적용하였다. ARIANE7을 사용하여 도출된 계류된 부유체의 운동 응답을 이용하여 계류라인의 최상부 장력에 대 한 시간 이력을 도출하고 피로 손상도를 계산하였다. 부유체에 적용된 오프셋은 $0 \sim 16 \mathrm{~m}$ 범위에서 $4 \mathrm{~m}$ 간격으로 부가하였으며, 부가된 강제 오프셋은 특정 계류라인의 장력이 가장 크게 걸리 는 방향으로 선정하였다.

Fig. 5 는 $12 \mathrm{~m}$ 의 오프셋을 가지는 부유체의 6자유도 운동 시계 열을 보여주는 것으로 선수요 및 좌우요의 경우 저주파수 응답 특성을 지배적으로 보이는 것을 확인할 수 있다.

Fig. 6은 피로 손상도의 대상이 되는 계류라인을 ORCAFLEX 를 이용하여 모델링한 그림을 보여준다. 전술한 방법으로 도출 된 부유체의 운동 응답 시계열을 계류라인 최상단에 강제 변위 로 부가하여 계류라인 장력의 시계열을 얻고자 하였다.

Fig. 7 은 $12 \mathrm{~m}$ 의 오프셋을 가지는 경우에 대한 계류라인 최상 단 장력의 시간이력을 나타낸 그림이다. 단기해상상태에 대한 피로 손상도를 얻기 위해 ORCAFLEX를 이용하여 3시간에 대한 비선형 과도 동적 응답해석을 수행하였으며 계류라인의 동적효 과 및 기하학적 비선형 효과가 고려되었다.

Fig. 8은 해석에 고려된 모든 입사각에 대한 계류라인 장력의 응답 스펙트럼의 0 차 모멘트를 도시한 그림이다. 장력에 대한 응답 스펙트럼은 과도 동적 응답해석을 통해 얻어진 장력 시계 열을 푸리에 변환하여 얻은 결과이다. Fig. 8에 의하면 모든 파 랑 입사각에 대해 초기 오프셋이 클수록 장력의 0 차 모멘트가
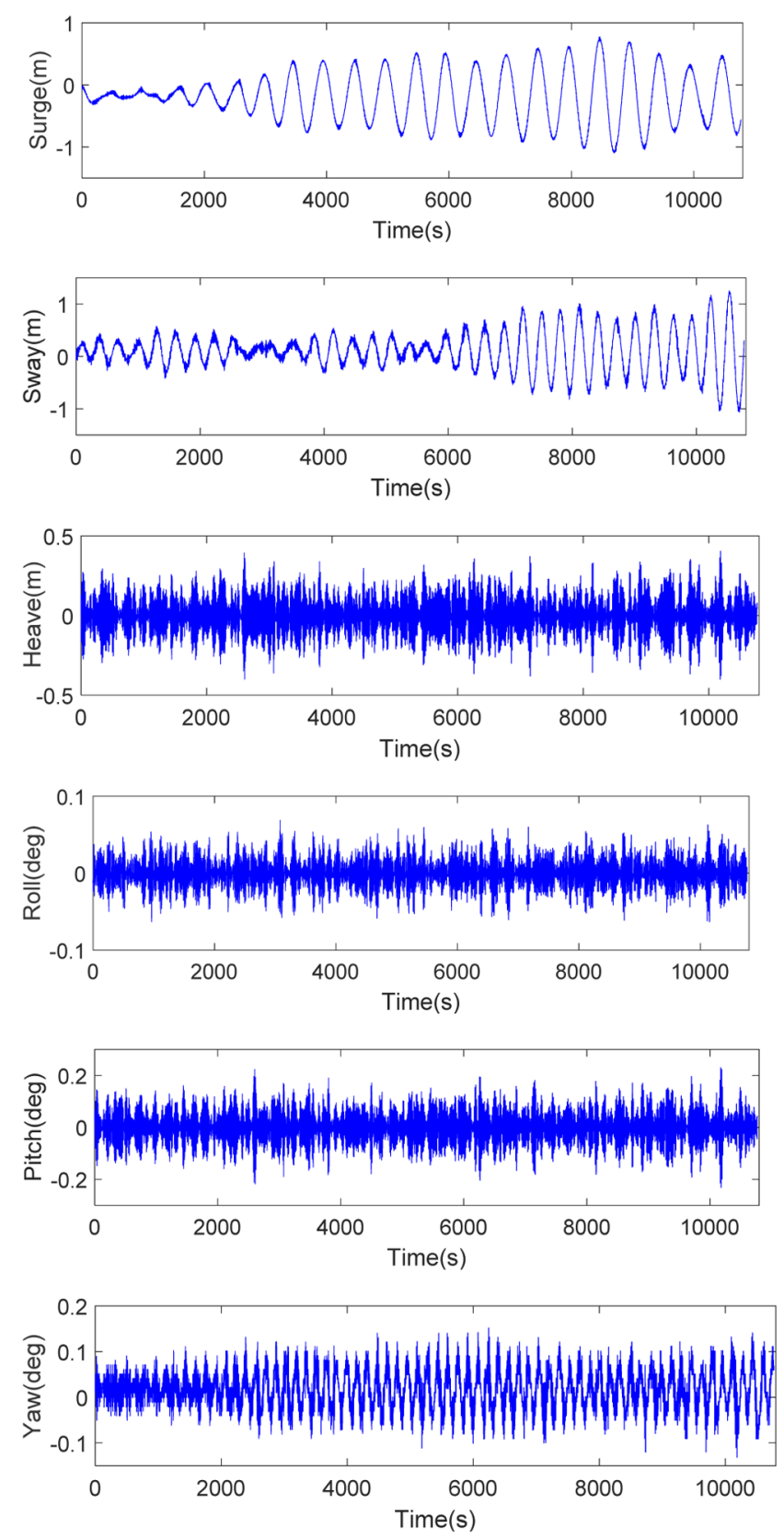

Fig. 5 Time history of floater motion at $12 \mathrm{~m}$ offset

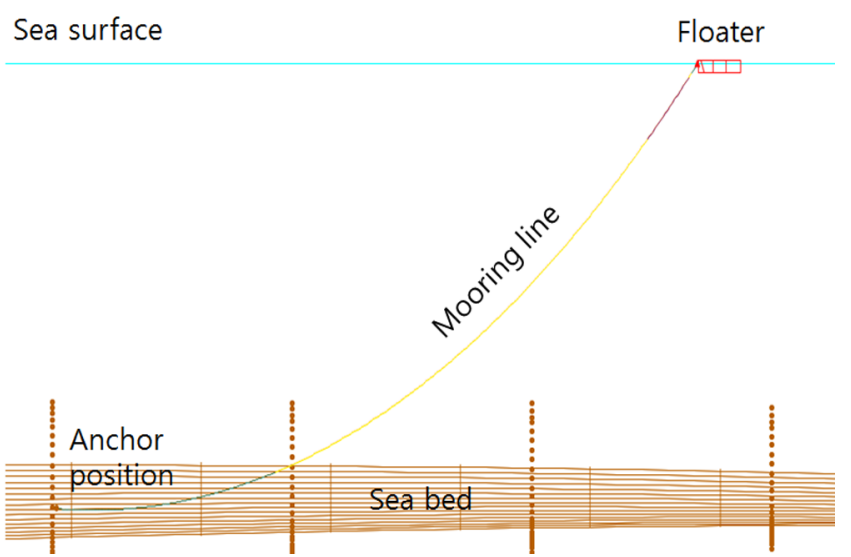

Fig. 6 Mooring line modeled in Orcaflex 


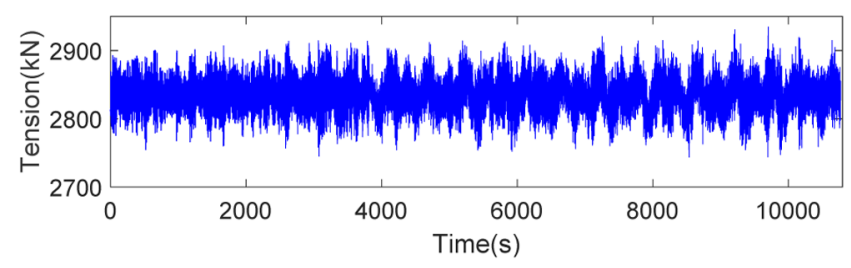

Fig. 7 Time history of mooring line top tension at $12 \mathrm{~m}$ offset

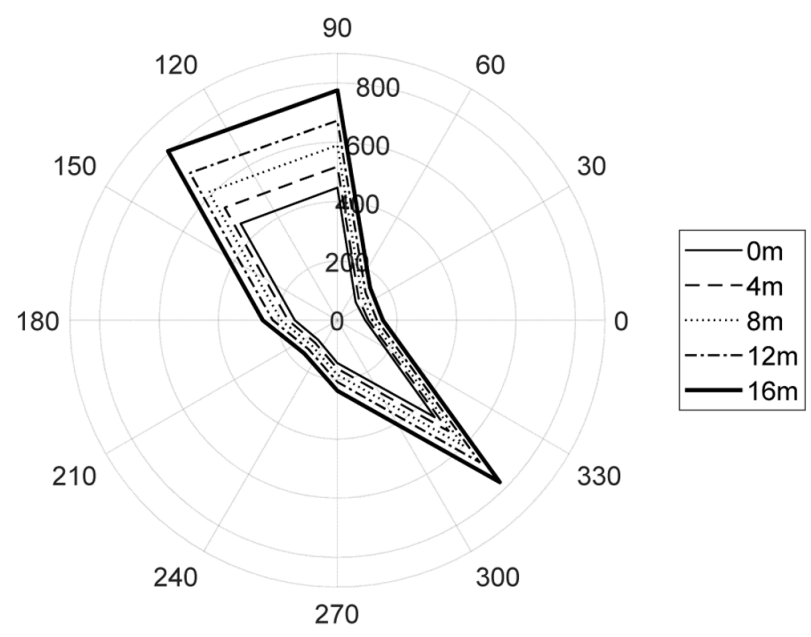

Fig. 8 Circumferential distribution of tension M0

증가하는 경향이 나타남을 알 수 있는데, 이는 초기 오프셋이 증가할수록 계류라인의 선인장력이 증가함으로 인한 결과로 판 단된다. 이러한 경향은 선인장력의 증가가 계류라인의 강성의 증가로 이어지고 이는 주어진 부유체의 운동 응답 하에서 더 큰 인장력을 유발한 결과로써 비연성 해법의 특성이라고 볼 수 있다.

인장력에 대한 응답 스펙트럼은 저주파수 성분과 파랑 주파수 성분이 혼재하여 나타나므로 스펙트럼의 0 차 모멘트가 단기 피 로손상도와 직결된다고 보기는 어렵다. 따라서, 해당 불규칙파가 야기하는 인장력에 대한 단기피로손상도를 계산하여 비교하는 작업을 수행하였다. 피로해석에 적용된 인장 $(\mathrm{R})-$ 수명 $(\mathrm{N})$ 선도 $\left(\mathrm{NR}^{\mathrm{M}}=\mathrm{K}\right)$ 는 $\mathrm{API} 2 \mathrm{SK}$ 에 제시된 값을 적용하였다 $(\mathrm{M}=3.0, \mathrm{~K}=316)$.

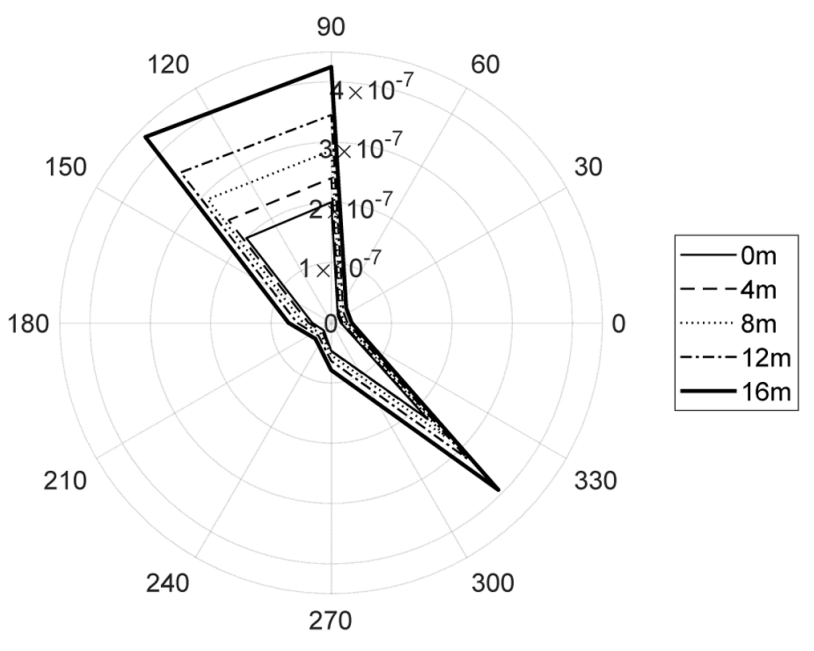

Fig. 9 Circumferential distribution of fatigue damage
Fig. 9는 입사각에 따른 단기 피로손상도의 분포를 나타낸다. 전반적으로 응답 스펙트럼의 분포와 유사한 양상을 띠고 있음 을 확인할 수 있으며, 입사각과 무관하게 초기 오프셋의 양이 클수록 피로 손상도가 크게 나타남을 확인할 수 있다.

\section{5. 사례 해석}

4절에서 검토된 오프셋의 효과를 바탕으로 대표 평균 위치를 이용한 방법의 실효성을 검증하기 위해 실 프로젝트 모델에 대 한 피로 해석을 수행하였다. 해양구조물의 설치 해역은 나이지 리아 남서쪽에 위치한 Bonga 해역의 Aparo로서 조류하중, 풍하 중 및 파랑하중에 대한 결합 확률 분포가 포함된 1,333 개의 단 기해상상태를 적용하였다. Fig. 10은 해석에 적용된 풍하중에 대한 로즈 다이어그램으로, $2 \mathrm{~m} / \mathrm{s}$ 의 속도 간격 및 45 도 간격의 입사각을 기반으로 작성되었다. 본 해상에서의 풍하중은 $5 \sim 7 \mathrm{~m} / \mathrm{s}$ 의 속력과 $180 \sim 270^{\circ}$ 의 입사각 범위에서 주로 발생하는 것을 확 인할 수 있다.

Fig. 11은 조류 하중에 대한 로즈 다이어그램으로, $0.2 \mathrm{~m} / \mathrm{s}$ 의 속도 간격 및 45 도 간격의 입사각을 기반으로 작성되었다. 조류 하중은 0.1 0.5m/s의 속력과 $180 \sim 315^{\circ}$ 의 입사각 범위에서 주로 발생하는 것을 확인할 수 있다.

서아프리카 해역의 파랑하중은 풍파(Wind sea)외에도 1차 및

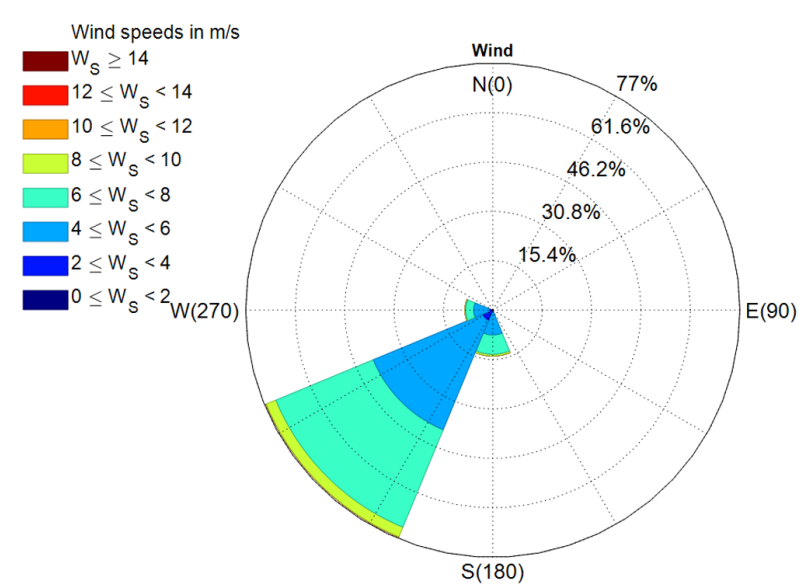

Fig. 10 Wind rose diagram

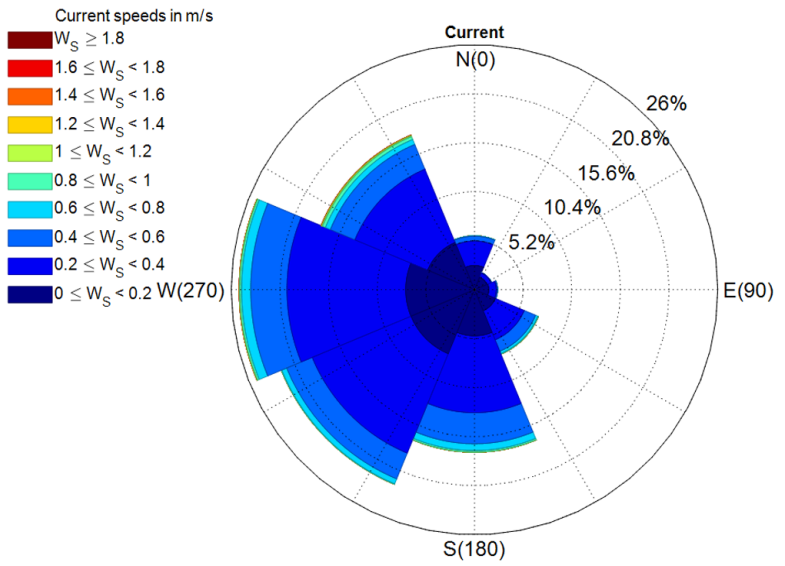

Fig. 11 Current rose diagram 
Table 3 Wave bin and representative value

\begin{tabular}{cccccc}
\hline \hline \multicolumn{2}{c}{ Hs } & \multicolumn{2}{c}{ Tp } & \multicolumn{2}{c}{ Heading } \\
Range & R.V & Range & R.V & Range & R.V \\
\hline \multirow{2}{*}{$0 \sim 1$} & \multirow{2}{*}{0.5} & $0 \sim 3$ & 1.5 & $337.5 \sim 22.5$ & 0 \\
& & $3 \sim 6$ & 4.5 & $22.5 \sim 67.5$ & 45 \\
\hline \multirow{3}{*}{$1 \sim 2$} & \multirow{2}{*}{1.5} & $6 \sim 9$ & 7.5 & $67.5 \sim 112.5$ & 90 \\
& & $9 \sim 12$ & 10.5 & $112.5 \sim 157.5$ & 135 \\
& & $12 \sim 15$ & 13.5 & $157.5 \sim 202.5$ & 180 \\
\hline \multirow{3}{*}{$2 \sim 3$} & \multirow{2}{*}{2.5} & $15 \sim 18$ & 16.5 & $202.5 \sim 247.5$ & 225 \\
& & $18 \sim 21$ & 19.5 & $247.5 \sim 292.5$ & 270 \\
& & $21 \sim 24$ & 22.5 & $292.5 \sim 337.5$ & 315 \\
\hline
\end{tabular}

2차 너울(Swell)의 효과가 크게 나타나므로 이에 대한 고려가 필요하다. 세 가지 파랑하중은 각각 서로 다른 유의파고, 모달 주기 및 입사각을 가지고 있으며, Table 3에 보인 바와 같이 적 절한 간격을 설정하여 파랑 분포도를 도출하여 적용하였다.

대표 평균 위치를 이용한 방법과 실제 평균 위치를 이용한 방 법을 1,333 개의 환경조건에 모두 적용하여 피로 손상도를 계산 하고, 두 가지 방법론으로 도출된 피로 손상도를 상호 비교하여 대표 평균 위치를 이용한 방법의 상대적 보수성을 평가하였다.

Fig. 12는 주어진 환경조건하에서 발생하는 조류하중과 풍하 중에 의해 발생하는 부유체의 실제 평균위치들과, 그들로부터 도출된 대표 평균 위치를 나타내고 있다. 사각형 표식은 부유체 의 초기위치를, 십자형 표식들은 조류하중과 풍하중에 의한 부 유체의 실제 평균 위치를, 그리고 원형 표식은 조류하중과 풍하 중에 의한 부유체의 대표 평균 위치를 나타낸다. 대부분의 실제 평균 위치는 부유체의 초기 위치에서 그리 멀지 않은 곳에 분 포하고 있음을 확인할 수 있으나, 장력이 크게 나타나는 평균 위치로부터 도출되는 대표 평균 위치는 상대적으로 초기 위치 로부터 상당히 떨어진 곳에 위치하고 있음을 확인할 수 있다.

실제 평균 위치는 해석에 고려된 1,333 개의 단기해상상태에 대한 결과이나, 대표 평균 위치의 경우 조류하중 및 풍하중에 따른 분류를 제외한 405 개의 단기해상상태에 대한 결과를 의미 한다.

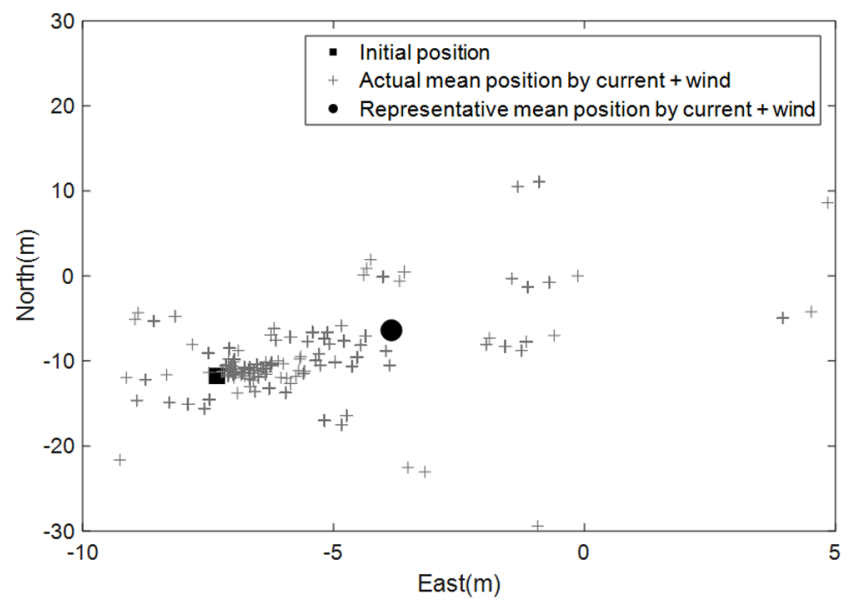

Fig. 12 Application of the representative mean position

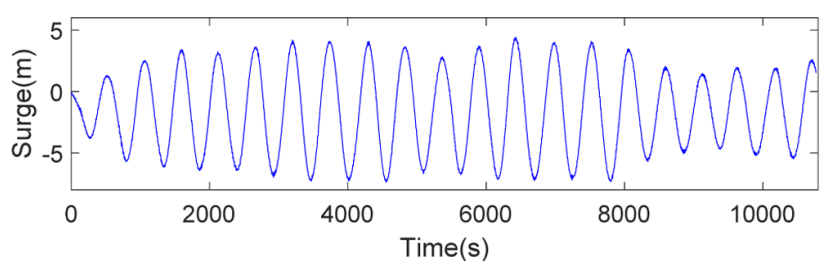

(a) Surge

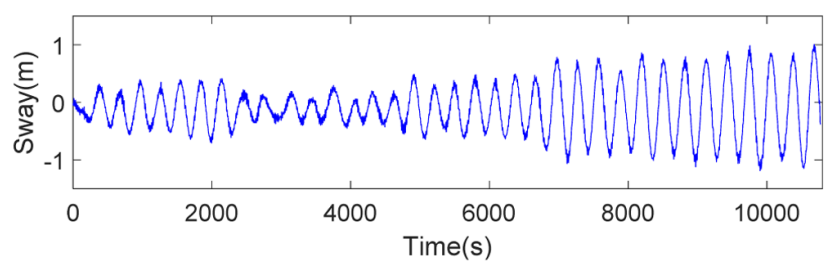

(b) Sway

Fig. 13 Surge and sway motion by actual mean position

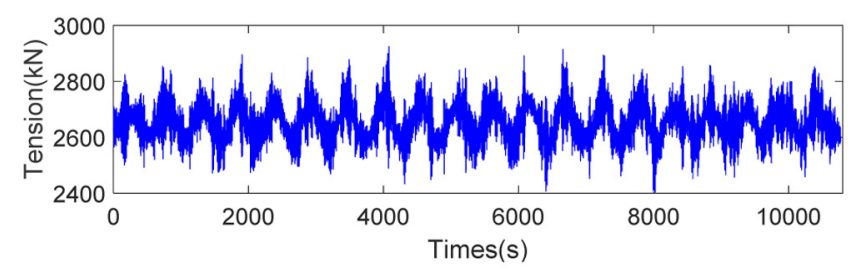

Fig. 14 Top tension by actual mean position

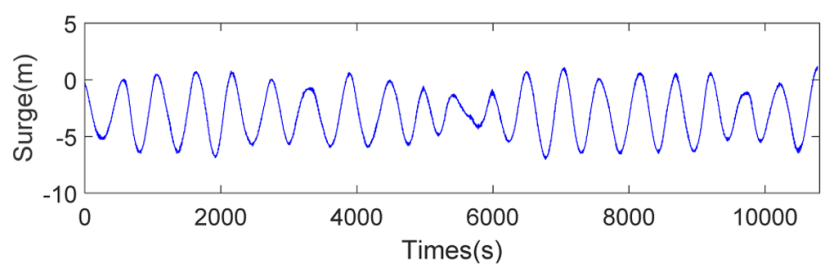

(a) Surge

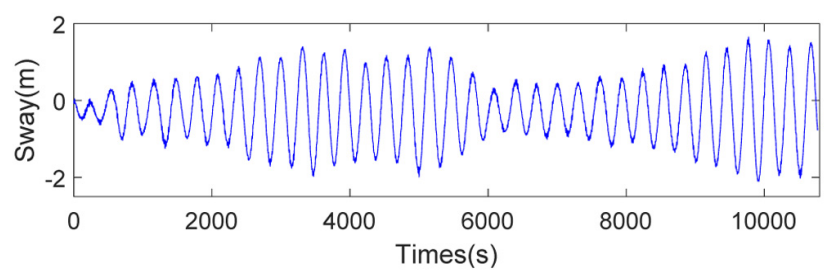

(b) Sway

Fig. 15 Surge and sway motion by representative mean position

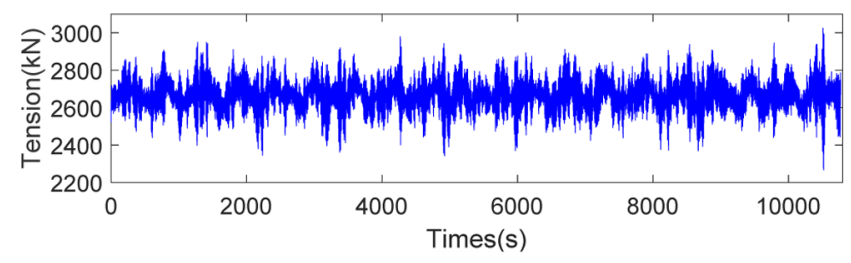

Fig. 16 Top tension by representative mean position

Fig. 13과 Fig. 14는 실제 평균 위치를 이용하여 얻어진 부유 체의 운동응답과 계류라인 최상단 장력의 시계열을 예시적으로 
도시한 그림이며, Fig. 15와 Fig. 16은 대표 평균 위치를 이용하 여 얻어진 결과의 예시를 보여준다.

실제 평균 위치를 이용한 방법으로 도출한 1,333 개의 장력 시 계열과 대표 평균 위치를 이용한 방법으로 도출한 405 개의 장 력 시계열에 레인플로우 집계법을 적용하여 장력 진폭에 대한 히스토그램을 도출한 결과를 Fig. 17 및 Fig. 18에 도시하였다. 대표 평균 위치를 이용한 경우 장력 진폭이 작은 경우에 발현 횟수가 상대적으로 적으나, 반대로 장력 진폭이 큰 경우 발현 횟수가 실제 평균 위치의 그것을 상회함을 확인할 수 있고 이 는 피로 손상도의 증가로 이어질 것임을 예측할 수 있다.

Table 4는 Fig. 18에 도출된 응력진폭에 대한 히스토그램을 이 용하여 예측된 피로 손상도를 보여주는 것으로 피로 손상도 계 산에 사용된 인장력-수명 선도는 앞서 사용된 것과 같다. 표에 보이는 바와 같이 대표 평균 위치를 사용하여 도출된 피로 손 상도는 실제 평균 위치를 사용하여 도출된 피로 손상도 대비 약 2 배 정도 큰 값을 보임을 확인할 수 있다. 이러한 결과는 대 표 평균 위치를 적용한 경우 선인장력의 증가로 인해 인장력의 변동 폭이 상대적으로 크게 나타나기 때문이며, 피로 손상도의 보수성은 대표 평균 위치를 선정할 때 사용되는 상위 인장력 유발 위치의 샘플 개수를 조절함으로써 가능하다.

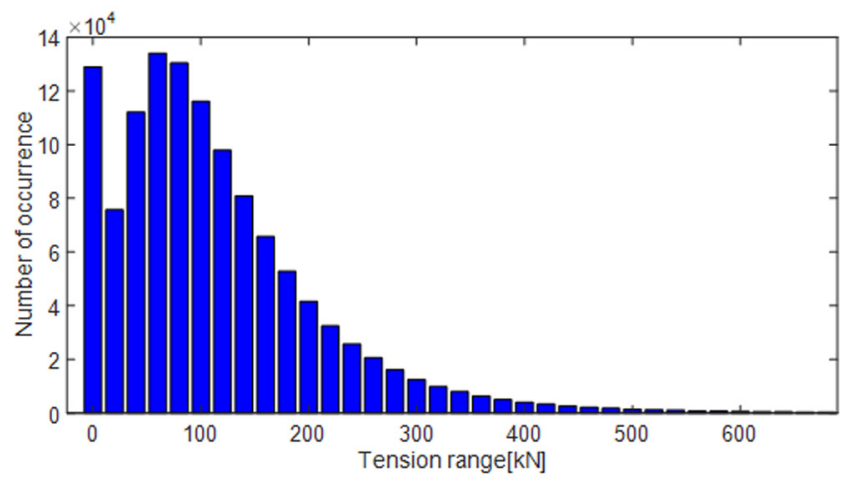

Fig. 17 Histogram of actual mean position method

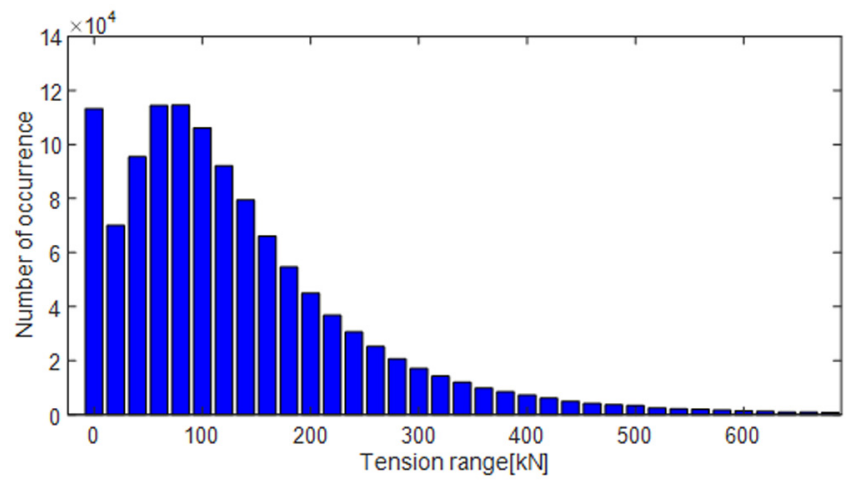

Fig. 18 Histogram of representative mean position method

Table 4 Calculated fatigue damage

\begin{tabular}{ccc}
\hline \hline & $\begin{array}{c}\text { Representative } \\
\text { mean position }\end{array}$ & $\begin{array}{c}\text { Actual } \\
\text { mean position }\end{array}$ \\
\hline Fatigue damage & $7.76 \mathrm{E}-06$ & $3.95 \mathrm{E}-06$ \\
\hline
\end{tabular}

\section{6. 결 론}

본 논문에서는 연성된 부유체-계류라인의 시간 영역 피로 해 석 효율화를 위해 대표 평균위치를 적용하여 계류라인의 피로 해석에 미치는 영향을 알아보았다. 오프셋에 기반을 둔 대표 평 균 위치의 유효성을 입증하기 위해 오프셋 효과 해석을 수행하 였다. 서로 다른 오프셋을 갖는 계류된 부유체에 전 방향으로 파랑하중을 부여하여 계류라인의 피로 손상도를 도출하고 파랑 하중의 입사각에 관계없이 오프셋이 커질수록 계류라인에 발생 하는 피로 손상도가 증가함을 확인하였다. 이어서, 대표 평균위 치를 이용한 방법의 실효성을 검토하기 위해 사례 해석을 수행 하였다. 사례 해석을 위해 해양구조물은 FPSO로, 설치 해역은 서아프리카 해역으로 가정하고 조류하중, 풍하중 그리고 파랑 하중 정보가 담긴 1,333 개의 해상조건을 사용하였다. 1,333 개의 해상조건에 대표 평균위치를 이용한 방법과 실제 평균 위치를 이용한 방법을 적용하여 피로 손상도를 도출하였으며, 두 결과 의 상호비교를 통해 대표 평균 위치의 유효성을 입증하였다. 본 연구를 통해 도출된 결론은 다음과 같이 요약 가능하다.

(1) 오프셋의 증가에 따라 계류라인의 선인장력이 증가하게 되고 이로인해 계류라인에 작용하는 변동 인장력의 진폭이 증 가한다. 결과적으로 이는 계류라인의 피로 손상도 예측치의 증 가로 이어진다.

(2) 조류하중과 풍하중의 정적 해석으로부터 발생하는 실제 평균 위치들을 하나의 대표 평균 위치로 설정함으로써 계류라 인의 동적 해석을 수행하는 경우, 결합확률을 고려한 단기해상 상태의 개수를 줄일 수 있으며 이는 시간영역해석의 효율화로 연결된다.

(3) 대표 평균 위치를 적용함으로써 시간영역해석을 필요로 하는 단기해상상태의 개수가 기존의 $30 \%$ 수준으로 줄어들었으 며 이는 계산 시간의 단축을 통한 피로해석의 효율화와 직결되 는 결과이다.

본 연구를 통하여 계류라인의 피로해석에 있어 대표 평균 위 치를 적용함으로 인해 보수적인 피로 손상도 및 시간영역 피로 해석의 수치 효율성을 동시에 확보 가능함을 확인하였다. 추가 적으로 대표 평균 위치의 상위 백분율 등의 조정을 통해 지나 치게 보수적인 피로 손상도를 회피할 수 있는 방안에 대한 추 가적인 연구가 필요할 것으로 판단된다.

\section{References}

Bureau Veritas, 2012. ARIANE7 Theoretical Manual, France.

Det Norske Veritas(DNV), 2010. Position Mooring, DNV-OS-E301, Norway.

Harald, O., Halvor, L., Carl, S., 2005. Coupled Analysis of Offshore Floating Systems. WIT Transactions on State of the Art in Science and Engineering, 18.

Harald, O., Sødahl, N., Steinkjer, O., 1998. Efficient Analysis of Mooring Systems using de-coupled and Coupled Analysis. OMAE98-0351.

Kang, C., Lee, C., Jun, S., Oh, Y., 2016. Fatigue Analysis of Spread 
Mooring Line. International Journal of Geological and Environmental Engineering, 10(5), 505-510.

Kim, Y., 2017. A Practical Procedure for Prediction of Extreme Loads on Offshore Mooring Lines. 36th Hydro-Seminar, Osaka University, Osaka.

Low, Y.M., Langley, R.S., 2008. A Hybrid Time/Frequency Domain
Approach for Efficient Coupled Analysis of Vessel/Mooring/ Riser Dynamics. Ocean Engineering, 35(5-6), 433-446.

Low, Y.M., 2011. Extending a Time/Frequency Domain Hybrid Method for Riser Fatigue Analysis. Applied Ocean Research, 33, 793-803. 